\title{
Re-engineering Primary Epithelial Cells from Rhesus Monkey Parotid Glands for Use in Developing an Artificial Salivary Gland
}

\author{
SIMON D. TRAN, D.M.D., Ph.D., ${ }^{1,2}$ TAKAYUKI SUGITO, D.D.S., Ph.D., ${ }^{1}$ \\ GIOVANNI DIPASQUALE, Ph.D., ${ }^{1}$ ANA P. COTRIM, D.D.S., Ph.D., \\ BIDHAN C. BANDYOPADHYAY, Ph.D., ${ }^{1}$ KATHRYN RIDDLE, Ph.D., ${ }^{3}$ \\ DAVID MOONEY, Ph.D., ${ }^{4}$ MARC R. KOK, M.D., Ph.D., ${ }^{1,5}$ JOHN A. CHIORINI, Ph.D., \\ and BRUCE J. BAUM, D.M.D., Ph.D. ${ }^{1}$
}

\begin{abstract}
There is no satisfactory conventional treatment for patients who experience irreversible salivary gland damage after therapeutic radiation for head and neck cancer or because of Sjögren's syndrome. Additionally, if most parenchyma is lost, these patients also are not candidates for evolving gene transfer strategies. To help such patients, several years ago we began to develop an artificial salivary gland. In the present study, we used a non-human primate tissue source, parotid glands from rhesus monkeys, to obtain potential autologous graft cells for development of a prototype device for in situ testing. Herein, we present 3 major findings. First, we show that primary cultures of rhesus parotid gland (RPG) cells are capable of attaining a polarized orientation, with $\mathrm{Na}^{+} / \mathrm{K}^{+}$-adenosine triphosphatase, zonula occludens-1, and claudin-1 distributed in specific domains appropriate for epithelial cells. Second, we show that RPG cells exhibit 2 essential epithelial functions required for graft cells in an artificial salivary gland device (i.e., an effective barrier to paracellular water flow and the generation of a moderate transepithelial electrical resistance). Third, we show that RPG cells can express functional water channels, capable of mediating directional fluid movement, after transduction by adenoviral and adeno-associated virus type 2 vectors. Together these results demonstrate that it is feasible to individually prepare RPG cells for eventual use in a prototype artificial salivary gland.
\end{abstract}

\section{INTRODUCTION}

$\mathbf{T}$ HE PRIMARY FUNCTION OF SALIVARY GLANDS is to produce an exocrine secretion, saliva, which plays an essential role in the protection and maintenance of the tissues of the upper gastrointestinal (GI) tract, as well as in initial food digestion. ${ }^{1}$ Not surprisingly, patients who lack adequate salivary gland function, for whatever reason, suffer from dysphagia, frequent oral soft and hard tissue infections (e.g., candidiasis, dental caries), diminished mucosal wound healing, and considerable pain and discomfort. ${ }^{2,3}$

\footnotetext{
${ }^{1}$ Gene Therapy and Therapeutics Branch, National Institute of Dental and Craniofacial Research, National Institutes of Health, Bethesda, Maryland.

${ }^{2}$ Faculty of Dentistry, McGill University, Montreal, Quebec, Canada

${ }^{3}$ Department of Chemical Engineering, University of Michigan, Ann Arbor Michigan.

${ }^{4}$ Division of Engineering and Applied Sciences, Harvard University, Cambridge, Massachusetts.

${ }^{5}$ Department of Clinical Immunology and Rheumatology, Academic Medical Center, Amsterdam, the Netherlands.
} 
There are 2 common reasons for the irreversible loss of salivary gland function: the autoimmune disorder Sjögren's syndrome and the radiotherapy that is part of the treatment for head and neck cancers. Patients with these conditions, for different etiopathologic reasons, experience the loss of the fluid- and protein-secreting acinar cells, and their salivary secretion is dramatically reduced. For many, most or all of the gland tissue is obliterated, leaving a massive inflammatory cell infiltrate (Sjögren's syndrome) or substantial fibrosis (both conditions). Such patients have little to no epithelial tissue remaining, rendering them inappropriate candidates for gene transfer strategies that currently are being evaluated. ${ }^{4-7}$

In an effort to help these patients, several years ago we began efforts to develop an artificial salivary gland. ${ }^{8-10}$ The envisioned device consists of a blind-end tube constructed of a biodegradable polymer (poly-L-lactic acid; PLLA), coated on its inner (luminal) surface with an extracellular matrix protein (e.g., fibronectin, collagen I), upon which sits a monolayer of polarized epithelial cells capable of unidirectional fluid movement. ${ }^{10}$ A major hurdle in the development of this device has been the latter component. ${ }^{11}$ Recently, we developed a method to obtain primary salivary epithelial cells capable of forming a polarized monolayer. ${ }^{12}$ These cells were apparently of ductal origin, and thus, are incapable of unidirectional fluid secretion. ${ }^{13-15}$ A significant hurdle in developing this device is the choice of an appropriate model for testing a prototype in vivo, because conventional rodent models are too small for effective testing of the in situ placement and function of an artificial salivary gland. ${ }^{16}$

In the present study, we used a non-human primate tissue, parotid glands from rhesus monkeys, as a cell source. Rhesus monkeys provide a sizable animal suitable for eventual in vivo testing of a prototype device. Herein we report the successful isolation of primary salivary ductal epithelial cells, capable of attaining polarized-orientation and membrane barrier function. Using this model glandular epithelium, we also demonstrate functional re-engineering of these cells, with adenoviral and adeno-associated viral (AAV) vectors encoding the archetypical water channel aquaporin-1, ${ }^{17}$ leading to high levels of directional fluid movement.

\section{MATERIALS AND METHODS}

\section{Rhesus parotid gland cell preparation and culture}

Rhesus parotid glands (RPGs) were rinsed twice in Dulbecco's modified Eagle medium (DMEM) supplemented $200 \mathrm{U} / \mathrm{mL}$ penicillin and $200 \mu \mathrm{g} / \mathrm{mL}$ streptomycin (Biofluids, Rockville, MD) and then transferred to a $100-\mathrm{mm}$ dish with $3 \mathrm{~mL}$ DMEM to remove the fibrous capsule. Next, using curved scissors, the tissue was mechanically minced into a slurry, followed by incubation in $35 \mathrm{~mL}$ of "dissociation buffer" for 3 to $4 \mathrm{~h}$ at $37^{\circ} \mathrm{C}$, with vigorous vortexing every $30 \mathrm{~min}$. The dissociation buffer contained a mixture of
$0.2 \mathrm{U} / \mathrm{mL}$ Liberase Blendzyme\#3 and 0.1\% Trypsin (both from Roche Diagnostic/Boehringer, Indianapolis, IN) in DMEM. The cell suspension was centrifuged at $1500 \mathrm{rpm}$ for $5 \mathrm{~min}$, the supernatant was discarded, and the resulting cell pellet was resuspended in $10 \mathrm{~mL}$ Hepato-Stim medium (Becton Dickinson, Bedford, MA) supplemented with $5 \%$ antibiotic/antimycotic solution $(500 \mathrm{U} / \mathrm{mL}$ penicillin, $500 \mu \mathrm{g} / \mathrm{mL}$ streptomycin, and $12.5 \mu \mathrm{g} / \mathrm{mL}$ fungizone; Biofluids) and $1 \%$ glutamine. This cell suspension was then filtered through a $70-\mu \mathrm{m}$ cell strainer (Becton Dickinson), then plated on a $100-\mathrm{mm}$ tissue culture dish, and incubated at $37^{\circ} \mathrm{C}$ overnight in $5 \%$ carbon dioxide $\left(\mathrm{CO}_{2}\right)$. Thereafter, the culture medium was changed twice a week, and the cells were passaged, at a 1:3 split ratio, using trypsin/versene (0.05\% trypsin, $0.02 \%$ versene; Biofluids) when the plate reached $70 \%$ to $80 \%$ confluence. Typically, cells reached this stage of confluence in 7 to 10 days. For most experiments reported herein, RPG cells from passages 2 to 4 were employed. These cells were in culture from 3 to 8 weeks. Some cells at passage 1 were stored in liquid nitrogen in a mixture of $90 \%$ Hepato-STIM medium and $10 \%$ dimethyl sulfoxide. Frozen cells could be recovered after 3 months (longest time studied) of storage in liquid nitrogen. For experiments to assess cell polarity, to measure transepithelial electrical resistance (TER), or to assess fluid movement (see details below), the passaged cells were grown on a polyester filter (Transwell-Clear system; Corning Life Sciences, Acton, MA).

\section{Cell line culture conditions}

HSG cells (a generous gift of M. Sato, Tokushima University, Japan $)^{18}$ were maintained in a $1: 1$ mixture of DMEM/Ham's F-12 (Biofluids) supplemented with $10 \%$ fetal bovine serum (HyClone, Logan, UT), $100 \mathrm{U} / \mathrm{mL}$ penicillin, $100 \mu \mathrm{g} / \mathrm{mL}$ streptomycin, and $2.5 \mu \mathrm{g} / \mathrm{mL}$ Fungizone (Biofluids) and cultured in a humidified atmosphere of $5 \%$ $\mathrm{CO}_{2}$ at $37^{\circ} \mathrm{C}$. Madin-Darby canine kidney (MDCK)-II cells were obtained from Clontech (Palo Alto, CA) and were maintained in DMEM (Biofluids) with the same supplements and growth conditions as used for HSG cells.

\section{Antibodies}

Mouse anti-zonula occludens (ZO)-1, rabbit anticlaudin-1, and rabbit anti-claudin-3 antibodies were obtained from Zymed (San Francisco, CA). Mouse anti-E-cadherin, mouse anti-vimentin (BD Pharminogen, San Diego, CA), mouse anti- $\mathrm{Na}^{+} / \mathrm{K}^{+}$-adenosine triphosphatase (ATPase) (Upstate Biotechnology, Lake Placid, NY), and rabbit antiaquaporin (AQP)1 (Alpha Diagnostic, San Antonio, TX) were obtained as indicated. These antibodies are reactive against their respective proteins from monkeys, humans, and several other species. Secondary antibodies, fluorescein (FITC)-conjugated AffiniPure $\mathrm{F}\left(\mathrm{ab}^{\prime}\right)_{2}$ fragment, donkey anti-rabbit immunoglobulin (Ig)G, and donkey anti-mouse 
IgG, were obtained from Jackson Immunoresearch Laboratories (West Grove, PA).

\section{Confocal microscopy}

Immunofluorescent staining was performed as described previously. ${ }^{12}$ Cells, grown on Transwell-Clear filters, were initially rinsed twice with phosphate-buffered saline (PBS without calcium and magnesium; $\mathrm{pH}$ 7.4; Biofluids) before being fixed with $3 \%$ paraformaldehyde in PBS for $30 \mathrm{~min}$. Thereafter, the cells were rinsed twice with PBS and treated with $100 \mathrm{mM}$ glycine in PBS for $20 \mathrm{~min}$. Cells were then permeabilized with methanol at $-20^{\circ} \mathrm{C}$ for $5 \mathrm{~min}$ and subsequently incubated in a mixture of 5\% donkey serum and $0.5 \%$ bovine serum albumin in PBS for $20 \mathrm{~min}$. Next, the cells were incubated with the appropriate primary antibody for $1 \mathrm{~h}$ at room temperature. Thereafter, the FITCconjugated secondary antibody was incubated for $30 \mathrm{~min}$, and cells were washed 3 additional times for 3 min each with PBS before the filter containing the cells was excised from its support and mounted onto a slide with Vectashield containing 4'-6-diamidino-2-phenylindole or propidium iodide (Vector Laboratories, Inc., Burlingame, CA). Expression of ZO-1, claudin-1, claudin- $3, \mathrm{Na}^{+} / \mathrm{K}^{+}$-ATPase, E-cadherin, and vimentin using confocal microscopy was observed using a Leica TCS SP2 scanner (Bensheim, Germany) with Leica confocal software.

\section{Measurement of TER and fluid movement}

Cells were seeded on 24-mm Transwell-Clear polyester filters and grown as above. The upper chamber containing the cells received $1.5 \mathrm{~mL}$ of medium, and the lower chamber received $2.6 \mathrm{~mL}$ of medium. TER was measured when the cells (RPG, MDCK, or HSG) were confluent, using a Millicell ERS epithelial volt-ohmmeter (Millipore Corp., Allen, TX) as described by the manufacturer. TER readings from filters without cells were subtracted from readings obtained from filters seeded with cells.

Transepithelial fluid movement was measured as described previously, ${ }^{12,19}$ using hyperosmotic medium in the apical chamber $(440 \mathrm{mosm})$ and isosmotic medium in the basal chamber ( 340 mosm). After the cells formed a confluent monolayer, $0.4 \mathrm{~mL}$ of normal growth medium supplemented with 100 mosm sucrose was put in the upper chamber, and $2.6 \mathrm{~mL}$ normal growth medium was put in the lower chamber. The cells were incubated for $30 \mathrm{~min}$ in a humidified atmosphere of $5 \% \mathrm{CO}_{2}$ at $37^{\circ} \mathrm{C}$, after which the medium in the upper chamber was removed and measured gravimetrically.

\section{Measurement of RPG cell growth on PLLA disks}

PLLA (Boehringer Ingelheim Inc., Winchester, VA) disks were produced by melt-processing polymer pellets between sheets of aluminum foil using a Carver press at $350^{\circ} \mathrm{F}$ to create disks with diameters of 20 to $25 \mathrm{~mm}$. The disks were sterilized in $80 \%$ ethanol for $30 \mathrm{~min}$. The sterilized disks were next coated using incubation in solutions of $20 \mu \mathrm{g} / \mathrm{mL}$ fibronectin (BD Biosciences, Bedford, MA) or $20 \mu \mathrm{g} / \mathrm{mL}$ collagen I (Cohesion Technologies, Inc., Palo Alto, CA) for $18 \mathrm{~h}$ at $37^{\circ} \mathrm{C}$. Thereafter, the disks were placed in each well of a 6-well tissue culture plate (Becton Dickinson, Franklin Lakes, NJ). Cell suspensions $\left(2.5 \times 10^{5}\right.$ RPG cells/well) were added in culture medium and incubated for up to 10 days. Cell number was measured as previously described. ${ }^{9}$ Briefly, at 2, 4, 6, 8, and 10 days, the disks were removed from the wells, stained with $0.2 \%$ crystal violet in $20 \%$ ethanol for $10 \mathrm{~min}$, and then rinsed twice with distilled water. Using an inverted light microscope, the cell number was counted in 3 randomly chosen $200-\mu \mathrm{m}^{2}$ regions from each disk.

\section{Recombinant virus production}

An adenovirus encoding human aquaporin-1 (AdhAQP1), an adenovirus encoding the green fluorescent protein (AdGFP), and an adeno-associated virus 2 encoding human aquaporin-1 (AAV2hAQP1) were constructed and purified, and titers were determined as described previously. ${ }^{4,19,20}$ Recombinant AAV2 and AAV5 vectors, containing a Rous sarcoma virus promoter GFP expression cassette, were produced as previously described, ${ }^{21}$ and particle titers determined using quantitative polymerase chain reaction. Before transduction, virus particles were dialyzed against DMEM for $3 \mathrm{~h}$ at room temperature. Dialyzed virus was then added to cells and incubated for the indicated times in DMEM. The following day, the virus-containing medium was removed and replaced with $200 \mu \mathrm{L}$ of complete media and the cells assayed for transduction.

\section{Transduction with AdhAQP1 and AAVhAQP1 promotes fluid movement}

After RPG cells formed a confluent monolayer on Transwell filters, they were incubated with AdhAQP1 or AdGFP vectors at a multiplicity of infection (MOI; defined as plaque-forming units/cell) of 1 on the apical surface. Transductions with AAV2hAQP1 and adeno-associated virus 2 encoding the green fluorescent protein (AAV2GFP) were performed at a MOI (defined as particles/cell) of 1000, also delivered at the apical surface. Fluid movement was measured, as described above, $24 \mathrm{~h}$ (AdhAQP1) or up to $72 \mathrm{~h}$ (AAV2hAQP1) after exposure to vectors to evaluate function of the transgenic hAQP1. Thereafter, the cells were stained with AQP1 antibody to detect hAQP1 and count the number of AQP1-positive cells. Cell number was counted in 3 rectangular frames under a microscope (Leica DM RE-7 SDK) at $100 \times$ magnification.

\section{Statistical analysis}

Data are reported as mean values \pm standard error of the mean. Significant differences in TER or fluid movement 


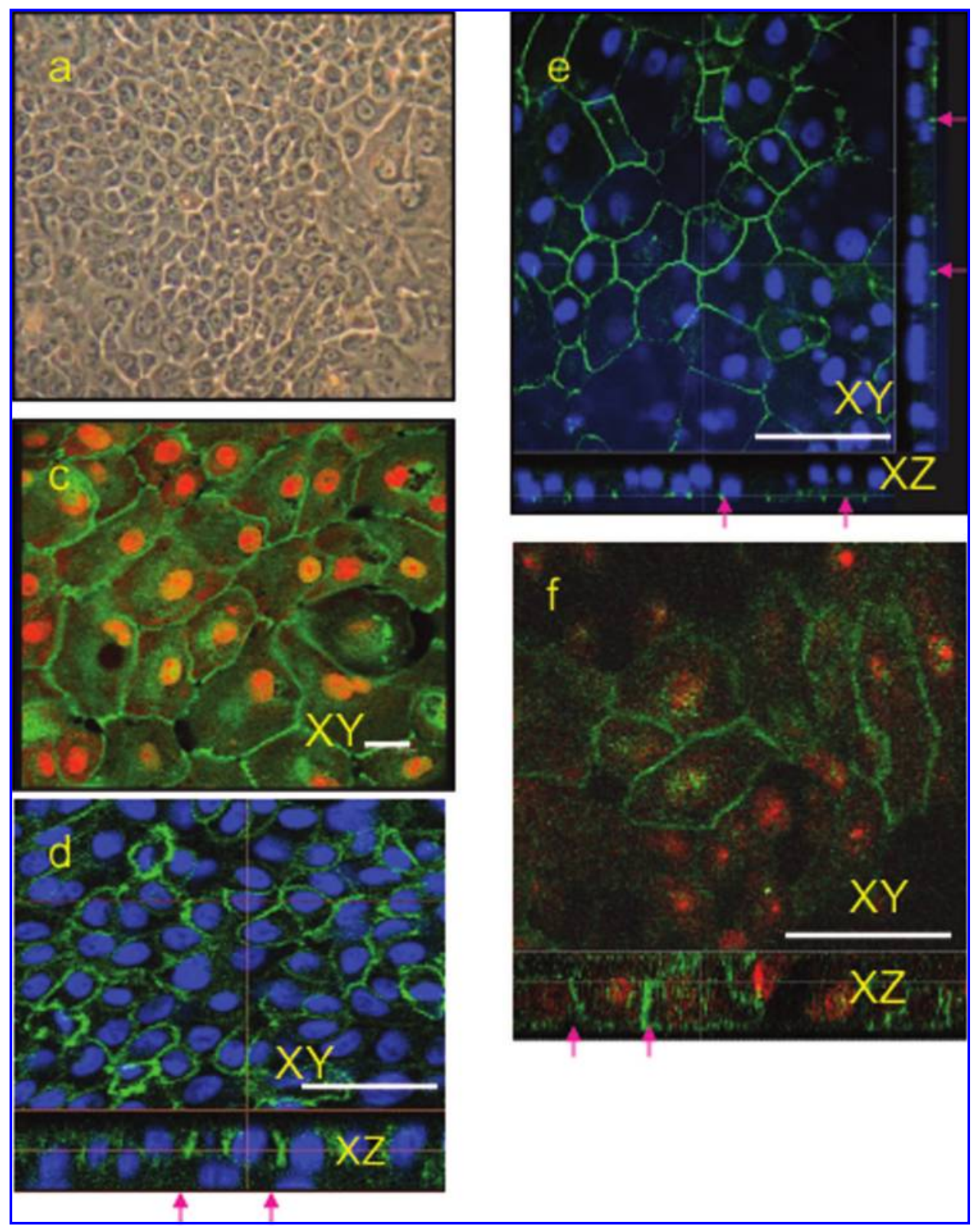

FIG. 1. Morphological and growth characteristics of rhesus parotid gland (RPG) cells. (A) Phase contrast micrograph showing the appearance of RPG cells during primary cell culture, typical for passages $1-4$. Magnification $100 \times$. (B) Time course of RPG cell growth on the poly-L-lactic acid (PLLA) disks coated with fibronectin or collagen I. RPG cells $\left(2.5 \times 10^{5}\right.$ cells $\left./ \mathrm{mL} ; 2 \mathrm{~mL}\right)$ were seeded on PLLA disks after coating overnight with fibronectin $(20 \mu \mathrm{g} / \mathrm{mL})$ or collagen I $(20 \mu \mathrm{g} / \mathrm{mL})$ and incubated for $2,4,6,8$, and 10 days. The results represent the average \pm standard error of the mean of 3 separate determinations. Inset photographs show the appearance of RPG cells on each of the above days and growth conditions after staining with $0.2 \%$ crystal violet in $20 \%$ ethanol. (C) Confocal photomicrograph showing the presence of the epithelial protein marker E-cadherin in RPG cells. Nuclei are stained with propidium iodide. Bar $=20 \mu \mathrm{m}$. (D) Confocal photomicrograph showing the distribution of the $\mathrm{Na}^{+} / \mathrm{K}^{+}$-ATPase in RPG cells. Nuclei are stained with DAPI. The X-Z image shows that $\mathrm{Na}^{+} / \mathrm{K}^{+}$-adenosine triphosphatase is localized to the basolateral membranes (arrow). Bar $=50 \mu \mathrm{m}$. (E) Confocal photomicrograph showing the localization of the tight junction protein zonula occludens (ZO)-1 in RPG cells. Nuclei are stained with 4'-6-diamidino-2-phenylindole. In the $\mathrm{x}-\mathrm{z}$ image, $\mathrm{ZO}-1$ is seen as distinct dots (arrows) appropriately localized toward the apical side. Bar $=50 \mu \mathrm{m}$. (F) Confocal photomicrograph showing the localization of claudin-1 in RPG cells. Nuclei are stained with propidium iodide. In the $\mathrm{x}-\mathrm{z}$ image, claudin-1 is seen localized in lateral membranes between neighboring cells (arrows). Bar $=50 \mu \mathrm{m}$. Color images available online at www.liebertpub.com/ten. 


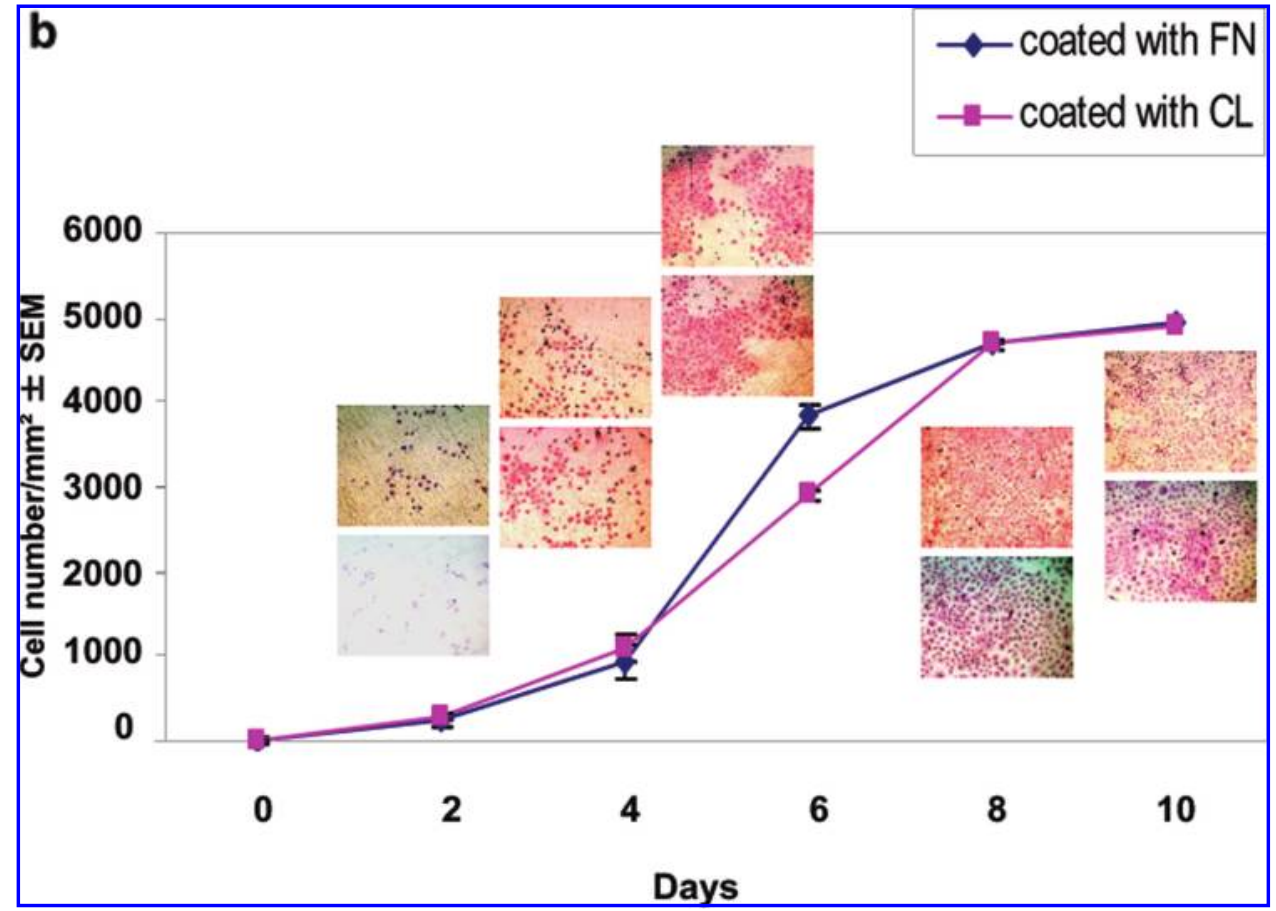

FIG. 1. (Continued)

were assessed using a 1-way analysis of variance followed by Fisher's protected least significant difference test.

\section{RESULTS AND DISCUSSION}

\section{Morphological characterization of rhesus parotid epithelial cells}

The mechanically and enzymatically digested rhesus parotid tissue initially consisted of floating clumps of cells. Within $6 \mathrm{~h}$ after plating, some cells (clumps) started to attach to the bottom of the dish. Small circumferential islands (10-20 cells) of epithelial-like cells were observed from day 1 after plating. As the cells proliferated and spread, these islands enlarged until they contacted each other to form an epithelial-like sheet of round, oval, and polygonal cells (Fig. 1A). The RPG cells took approximately 7 to 10 days to attain $80 \%$ confluence. When RPG cells were grown on disks composed of PLLA, a useful biodegradable substratum, coated with fibronectin or collagen I, the cell number increased slowly over the first 4 days. Thereafter, cell growth was rapid, increasing until day 8 , before reaching a plateau with RPG cells exhibiting an epithelioid appearance (Fig. 1B).

We next evaluated RPG cells for expression and localization of several key proteins using confocal microscopy. As shown in Fig. 1C, RPG cells uniformly express E-cadherin, which indicates their epithelial nature. When cells were probed with an antibody to vimentin, which is a marker of mesenchymal cells, they were uniformly negative (not shown). To assess whether the cells were morphologically polarized, we initially probed the cells with antibody to the $\mathrm{Na}^{+} / \mathrm{K}^{+}$-ATPase. In polarized epithelial cells, this molecule is found on the basolateral membranes. In RPG cells, the $\mathrm{Na}^{+} / \mathrm{K}^{+}$-ATPase was clearly localized to this membrane domain (Fig. 1D; $x-y$ and $x-z$ images). ZO-1 is a key tightjunction component, normally found toward the apical region between adjacent epithelial cells. ${ }^{22}$ As shown in Fig. $1 \mathrm{E}$, probing of RPG cells with antibody to ZO- 1 revealed the presence of hexagonal labeling of the plasma membrane in the $x-y$ plane, with a discrete dot-shaped localization toward the apical region when viewed in the $\mathrm{x}-\mathrm{z}$ plane. Claudin- 1 is another key component of tight junctions typically detected along the lateral membranes between neighboring cells. ${ }^{23} \mathrm{As}$ shown in Fig. 1F ( $\mathrm{x}-\mathrm{y}$ and $\mathrm{x}-\mathrm{z}$ images), incubating RPG cells with antibody to claudin-1 labeled the lateral membranes. RPG cells, however, were not stained with an antibody to claudin-3 (not shown), which suggested that they were of duct cell origin (Tran et al., unpublished). These aggregate results suggest that RPG cells attain a correct morphological polarization when grown in vitro on Transwell filters.

\section{Functional characterization of rhesus parotid epithelial cells}

We next examined 2 important functional aspects of a polarized epithelium in the RPG cell monolayers: the ability to generate a TER and to serve as a physiological barrier. Initially, we compared the TER generated by RPG cells with that of MDCK cells, as a positive control, and HSG cells, a cell line incapable of forming tight junctions, ${ }^{11}$ as a negative control. As shown in Fig. 2A, RPG cells were able to generate 


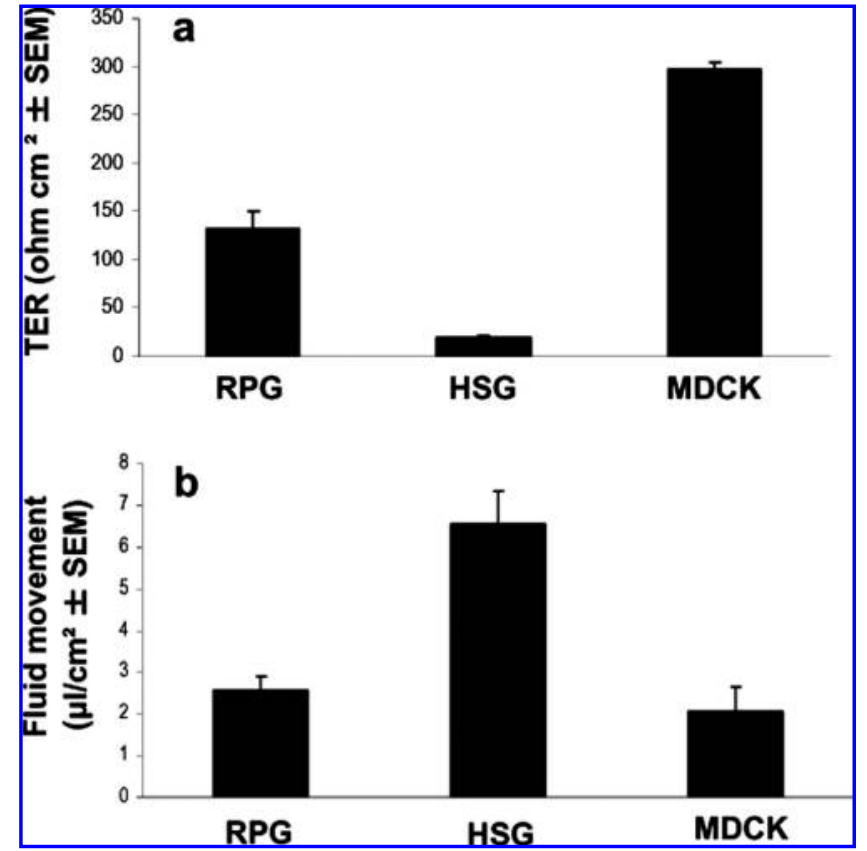

FIG. 2. Functional traits of rhesus parotid gland (RPG) cells. (A) Transepithelial electrical resistance (TER) was measured as described in Materials and Methods. Madin-Darby canine kidney (MDCK) cells are used as a positive control. RPG cells showed significantly higher TER than that of HSG cells, used as a negative control. The results represent the average \pm standard error of the man (SEM) of 5 separate determinations for RPG cells, 8 separate determinations for HSG cells, and 7 separate determinations for MDCK cells. (B) Paracellular fluid movement was measured as described in Materials and Methods. The restriction of fluid movement by RPG cells was significantly greater than that by HSG cells, which served as a negative control. MDCK cells are used as a positive control. The results represent the average \pm SEM of 4 separate determinations for RPG cells and 6 separate determinations each for HSG cells and MDCK cells. For these experiments, cells were seeded on day 0. Subsequently, on days $1-3$, cells were tested for TER, as well as observed microscopically for visual confluence. On day 3, RPG and MDCK cells achieved confluence according to visual examination and displayed high TER levels. Although HSG cells appeared to attain confluence visually at this time, they did not show elevated TER. Thus, before measuring fluid movement in these experiments, RPG and MDCK cells exhibited high TER.

a modest TER $\left(\sim 135 \Omega \cdot \mathrm{cm}^{2}\right)$, whereas MDCK cells displayed higher TER values $\left(\sim 300 \Omega \cdot \mathrm{cm}^{2}\right)$. HSG cells displayed very low TERs $\left(\sim 20 \Omega \cdot \mathrm{cm}^{2}\right)$. The TER levels generated by RPG cells $(p<0.01)$ and MDCK cells $(p<0.01)$ were significantly different from those of HSG cells.

Paracellular fluid movement was employed as an indicator of membrane barrier function, and we compared results with RPG, MDCK, and HSG cells. As shown in Fig. 2B, HSG cells, again used as a negative control, were unable to provide an effective barrier to fluid movement in response to an imposed osmotic gradient, 440 mosm apical to 340 mosm basal ( $\sim 6.5 \mu \mathrm{L} / \mathrm{cm}^{2}$ over $\left.30 \mathrm{~min}\right)$. Conversely, MDCK cells

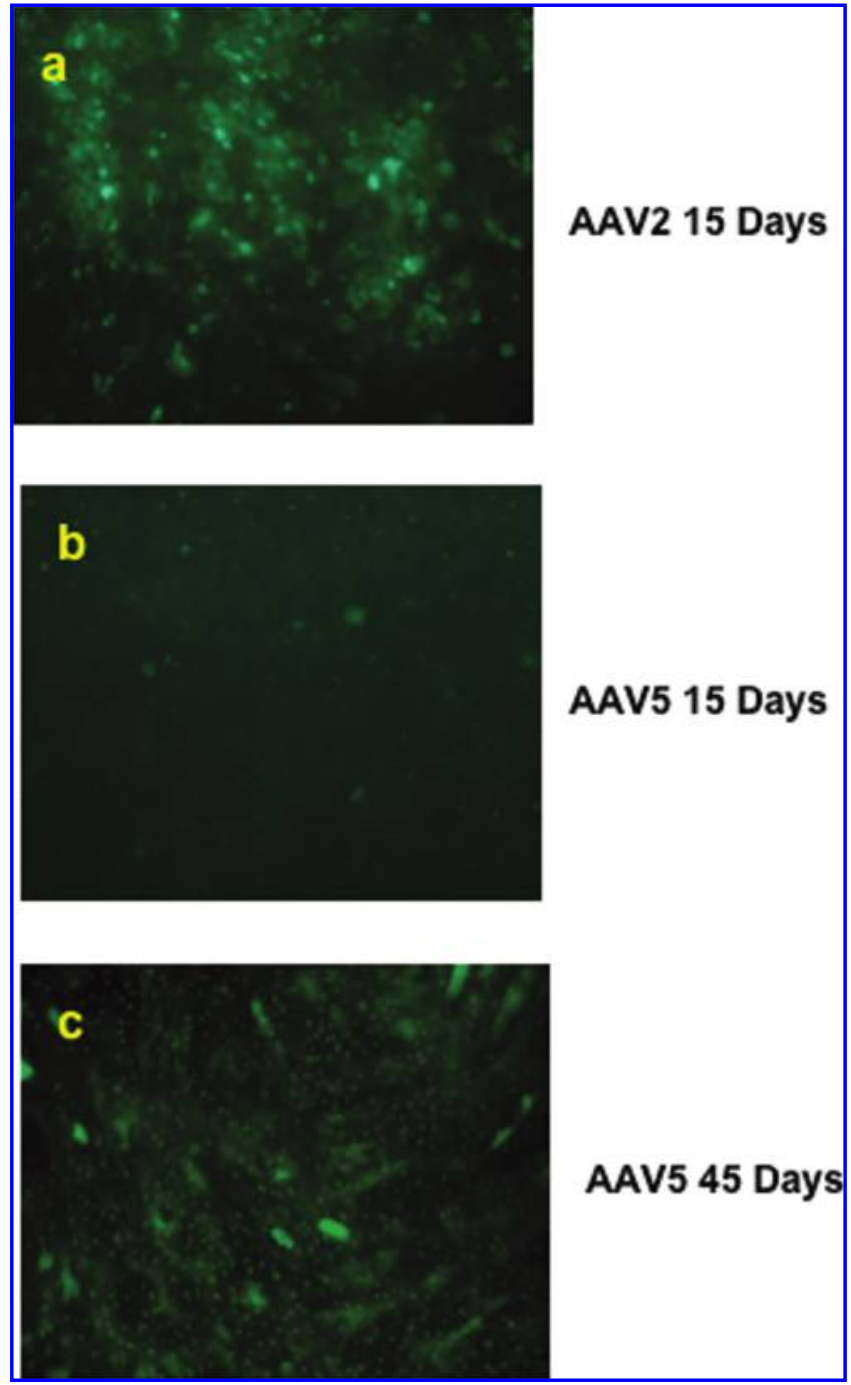

FIG. 3. Effect of adeno-associated virus type 2 (AAV2) and AAV5 vectors on transduction of rhesus parotid gland (RPG) cells. Primary cultures of RPG cells were transduced with AAV2 or AAV5 vectors encoding green fluorescent protein (GFP). RPG cells were incubated with $5 \times 10^{4}$ adeno-associated virus encoding the green fluorescent protein particles/cell. Pictures of GFPtransduced cells were taken using a Nikon DXM12000F digital camera mounted on a fluorescent microscope with a Nikon 10X, 0.25 N.A. objective. Images were acquired using Nikon ACT-1 software. Transduction was followed over time, and the percentage of transduced cells was quantified using manual counting. Specifically, the percentage transduction was determined as follows. The field was divided into quadrants, and the number of positive cells and the total number of cells in each quadrant were counted. Cells were counted in 2 independent fields in each experiment. (A) RPG cells 15 days post-transduction with the AAV2 vector. (B) RPG cells 15 days post-transduction with the AAV5 vector. (C) RPG cells 45 days post-transduction with the AAV5 vector. Data shown are representative of 2 independent experiments. Color images available online at www.liebertpub .com/ten. 
Table 1. Effect of Aquaporin-1 Encoding Viral Vectors on Fluid Movement Across Monolayers of Rhesus Parotid Gland (RPG) Cells

\begin{tabular}{lcc}
\hline Vector & $\begin{array}{c}\text { Adenovirus encoding human } \\
\text { aquaporin-1 positive cells }(\%)\end{array}$ & $\begin{array}{c}\text { Fluid movement }\left(\mu \mathrm{L} / \mathrm{cm}^{2} \pm\right. \\
\text { standard error of the mean })\end{array}$ \\
\hline AdGFP $^{1}$ & none & $1.4 \pm 0.7$ \\
AdhAQP1 $^{1}$ & $14.6 \pm 1.1$ & $5.0 \pm 0.4$ \\
AAV2GFP $^{2}$ & none & $0.9 \pm 0.2$ \\
AAV2hAQP1 & $9.2 \pm 1.7$ & $5.9 \pm 0.7$ \\
\hline
\end{tabular}

${ }^{1}$ Measured at $24 \mathrm{~h}$ post-transduction with multiplicity of infection $(\mathrm{MOI})=1$ plaque-forming unit/cell.

${ }^{2}$ Measured at $72 \mathrm{~h}$ post-transduction with MOI $=1000$ particles/cell.

The time points selected for performing fluid movement measurements were chosen for experimental convenience and because of clearly demonstrable human aquaporin-1 expression (see Fig. 4). For the experiments reported in this table, transepithelial electrical resistance (TER) was measured before and after transduction of RPG cells with the indicated vectors. These vectors had no effect on TER measurements; before performing fluid-movement assays, all RPG cells exhibited high TER. See Materials and Methods for additional details.

were able to effectively limit the movement of fluid from the basal to the apical culture chamber in response to this same osmotic gradient $\left(\sim 2.0 \mu \mathrm{L} / \mathrm{cm}^{2} ; p<0.01\right.$ vs $\mathrm{HSG}$ cells). RPG cells were able to limit the fluid movement almost as effectively as MDCK cells $\left(2.6 \mu \mathrm{L} / \mathrm{cm}^{2} ; p<0.01\right)$.

\section{Susceptibility of RPG cells to transduction with AAV serotypes 2 and 5}

Previously, we demonstrated that duct cells in murine salivary glands are permissive for several different serotypes of AAV but differ in their transduction activity. ${ }^{24-26}$ For example, although approximately $27 \%$ of the cells per duct were transduced with AAV2 vectors at 6 weeks postinfusion, approximately $46 \%$ were transduced with AAV5 vectors at the same dose when assayed using immunohistochemical staining for GFP expression. ${ }^{26}$ Similar differences in transduction activity were also observed with vectors encoding $\beta$-galactosidase and when using quantitative polymerase chain reaction to measure the number of vector genomes in isolated glands. ${ }^{26}$

We therefore compared the relative transduction activity of AAV2 and AAV5 vectors containing GFP expression cassettes in cultures of RPG cells over time. In agreement with previous reports of transduction experiments with primary cells, the kinetics of AAV vector transduction were considerably slower than that observed with established cell lines. ${ }^{27}$ At a MOI of $5 \times 10^{4}$ particles/cell, transduction was initially detected at 15 days post-incubation and differed substantially between the two serotypes (Fig. 3; AAV2 > AAV5). Although approximately $20 \%$ of the RPG cells incubated with AAV2 were positive for GFP expression at this time, fewer than $1 \%$ of the cells incubated with AAV5 were positive (Fig. 3A, B). However, by day 45 after exposure to vector, the relative transduction activity of the 2 vectors was different. AAV2 transduction remained at approximately $20 \%$ (not shown), but AAV5 transduction of RPG cells had increased to approximately $80 \%$ (Fig. 3C). At both time points, with both vectors, there was considerable variation from cell to cell in the level of GFP expression detected. Some RPG cells were highly transduced, whereas others exhibited only low levels of transduction. These general results mirror our earlier in vivo experiments with mice $^{26}$ and suggest that multiple serotypes of AAV will be useful for transducing primate salivary glands in vivo.

\section{Functional re-engineering of RPG cells}

Using the RPG cell model glandular epithelia, we tested the potential for functional re-engineering of these cells using adenoviral and AAV vectors encoding the archetypical water channel hAQP $1 .{ }^{17}$ Transfer of the hAQP1 cDNA with the AdhAQP1 vector is useful for correcting irradiation-induced salivary hypofunction in rats and minipigs. ${ }^{4,6}$ For these experiments, control RPG cells were transduced with vectors encoding GFP. There were no hAQP1-immuno-positive RPG cells observed $24 \mathrm{~h}$ after exposure to AdGFP (not shown), and the rate of fluid movement in response to an imposed osmotic gradient ( 440 mosm to 340 mosm; apical to basal) was $1.4 \mu \mathrm{L} / \mathrm{cm}^{2}$ per $30 \mathrm{~min}$ (Table 1). Conversely, $24 \mathrm{~h}$ after transduction with AdhAQP1 approximately $15 \%$ of the cells were hAQP1 immuno-positive (Fig. 4A), and their rate of fluid movement was elevated more than 3 -fold, to $5.0 \mu \mathrm{L} / \mathrm{cm}^{2}$ per $30 \mathrm{~min}$. Seventy-two h after transduction with AAV2hAQP1 ${ }^{19}$ approximately $9 \%$ of RPG cells were hAQP1 immuno-positive (Fig. 4B-D), and these cells also exhibited a marked increase ( $\sim 6$-fold) in the rate of fluid movement (Table $1 ; 5.9 \mu \mathrm{L} / \mathrm{cm}^{2}$ per $30 \mathrm{~min}$ ) versus that seen after transduction of cells with AAV2GFP $\left(0.9 \mu \mathrm{L} / \mathrm{cm}^{2}\right.$; no hAQP1 immuno-positive cells detected; not shown). Based on previous in vitro studies with a model polarized rat salivary epithelium in vitro, it is likely that even low levels of hAQP1 would be sufficient for achieving substantial transepithelial fluid movement in vivo. ${ }^{28}$ However, it may be that the levels of fluid movement achieved with RPG cells herein would be insufficient to provide adequate moisture for patients' mouths. In that case, it should be possible to increase the dose of vector used to transduce the cells, which consequently should lead to significant increases in fluid movement. $^{28}$ 


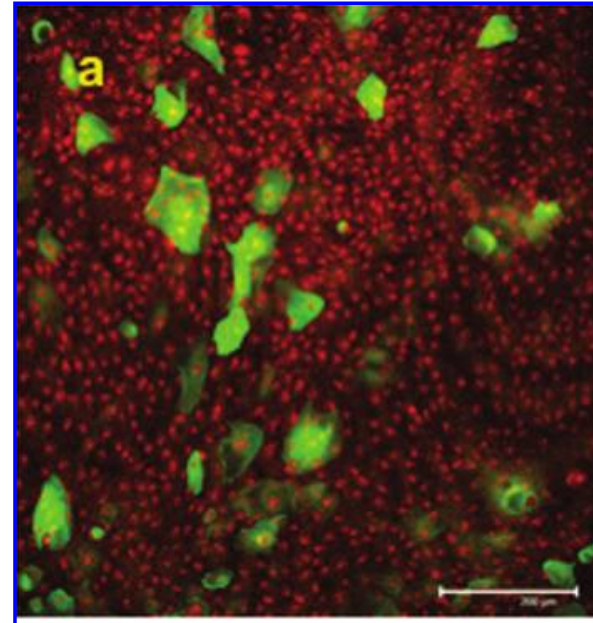

AdhAQP1

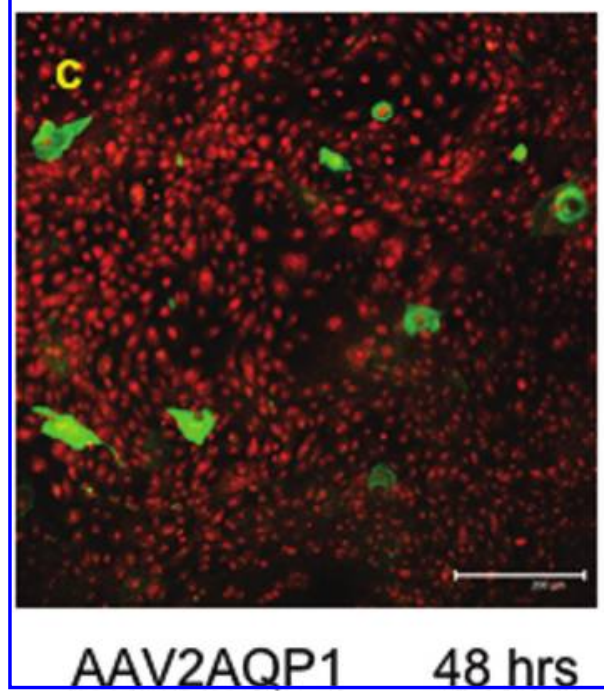

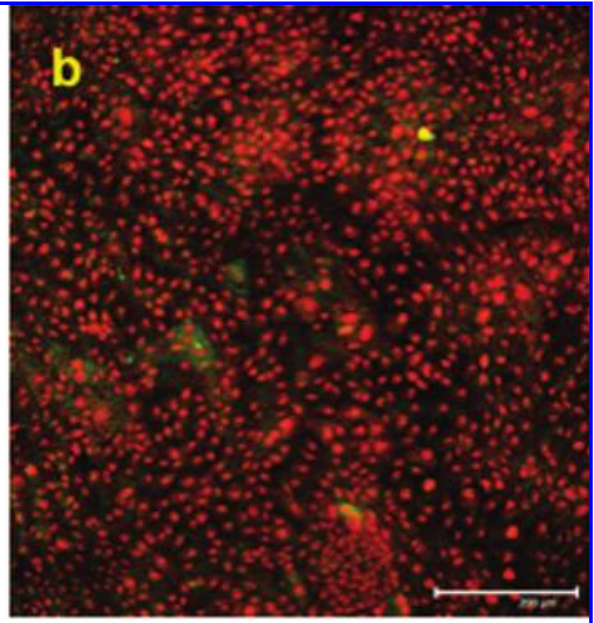

\section{AAV2AQP1 24hrs}

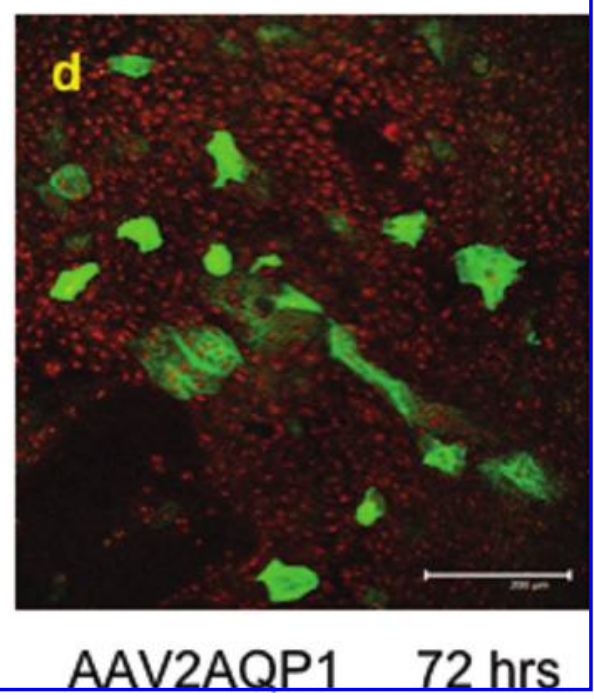

FIG. 4. Expression of human aquaporin-1 (hAQP1) in rhesus parotid gland (RPG) cells transduced with an adenovirus encoding human aquaporin-1 (AdhAQP1) or an adeno-associated virus encoding 2 human aquaporin-1 (AAV2hAQP1). RPG cells were exposed to AdhAQP1 for $24 \mathrm{~h}$ (multiplicity of infection $(\mathrm{MOI})=1$ ) or AAV2hAQP1 for $72 \mathrm{~h}(\mathrm{MOI}=1000)$, as described in Materials and Methods and in Table 1. Cells were stained with an antibody to hAQP1, and nuclei were labeled with propidium iodide. Bar $=200 \mu \mathrm{m}$. Color images available online at www.liebertpub.com/ten.

\section{CONCLUSIONS}

In the present study, we have achieved 3 major findings. First, we show that primary cultures of RPG cells are capable of attaining a polarized orientation, as demonstrated by the correct localization of $\mathrm{Na}^{+} / \mathrm{K}^{+}$-ATPase, ZO1 , and claudin- $1 .{ }^{22,23}$ Second, we show that RPG cells exhibit an essential epithelial function required for graft cells in an artificial salivary gland device: the presence of an effective membrane barrier limiting paracellular water permeability and resulting in a significant TER. Third, we show that RPG cells can express functional water channels, capable of mediating directional fluid movement, after transduction by adenoviral and AAV2 vectors encoding
hAQP1. These results indicate that it is feasible to achieve the functional re-engineering of such duct-like cells for their eventual use in an artificial salivary gland. It remains to be shown whether RPG cells are capable by themselves of generating an osmotic gradient and driving fluid secretion through the transferred AQP1 channels or whether further re-engineering would be required (e.g., insertion of $\mathrm{Cl}^{-}$entry or exit pathways). ${ }^{14,15}$ Such re-engineering, at least for testing a prototype, could be achieved with AAV2 or AAV 5 vectors. Both vector serotypes convey considerable stability of transgene expression when used to transduce murine salivary duct cells. ${ }^{24,26}$

In aggregate, we suggest that these findings provide a strong impetus for the development of a prototype device 
capable of being tested in vivo in rhesus monkeys. As we previously showed, for in situ testing of a functional artificial salivary gland, a large animal is required, as is an autologous graft cell. ${ }^{11,16}$ As shown herein, rhesus parotid glands provide an excellent model for such studies. Each individual animal could provide a cell source via a biopsy of the tail region of the parotid gland with minimal morbidity. While the biopsy site healed, cells could be prepared and re-engineered as required and the device fabricated. Thereafter, it could be implanted via a small incision (pouch) in the buccal mucosa, sutured to provide an orifice, and tested for secretion after healing of the surgical wound. If effective, such a device could provide benefit to many patients who currently lack satisfactory treatment options. ${ }^{29,30}$

\section{ACKNOWLEDGMENTS}

We thank Dr. Kenneth Yamada for providing the initial samples of fibronectin used herein and Dr. Jianghua Wang for help with preliminary experiments. This research was supported in part by the Intramural Research Program of the National Institute of Dental and Craniofacial Research, National Institute of Health. S.D. Tran is supported by grants from Canadian Institutes of Health Research/ Institute of Musculoskeletal Health and Arthritis and a Canada Research Chair.

\section{REFERENCES}

1. Amerongen, A.V., and Veerman, E.C. Saliva-the defender of the oral cavity. Oral Dis. 8, 12, 2002.

2. Kaplan, M.D., and Baum, B.J. The functions of saliva. Dysphagia 8, 225, 1993.

3. Fox, P.C. Acquired salivary dysfunction. Drugs and radiation. Ann. N. Y. Acad. Sci. 842, 132, 1998.

4. Delporte, C., O'Connell, B.C., He, X., Lancaster, H.E., O'Connell, A.C., Agre, P., and Baum, B.J. Increased fluid secretion after adenoviral-mediated transfer of the aquaporin1 cDNA to irradiated rat salivary glands. Proc. Natl. Acad. Sci. U. S. A. 94, 3268, 1997.

5. Kok, M.R., Yamano, S., Lodde, B.M., Wang, J., Couwenhoven, R.I., Yakar, S., Voutetakis, A., Leroith, D., Schmidt, M., Afione, S., Pillemer, S.R., Tsutsui, M.T., Tak, P.P., Chiorini, J.A., and Baum, B.J. Local adeno-associated virus-mediated interleukin 10 gene transfer has diseasemodifying effects in a murine model of Sjogren's syndrome. Hum. Gene Ther. 14, 1605, 2003.

6. Shan, Z., Li, J., Zheng, C., Liu, X., Fan, Z., Zhang, C., Goldsmith, C.M., Wellner, R.B., Baum, B.J., and Wang, S. Increased fluid secretion after adenoviral-mediated transfer of the human aquaporin-1 cDNA to irradiated miniature pig parotid glands. Mol. Ther. 11, 444, 2005.

7. Lodde, B.M., Mineshiba, F., Wang, J., Cotrim, A.P., Afione, S., Tak, P.P., and Baum, B.J. Effect of human vasoactive intestinal peptide gene transfer in a murine model of Sjögren's syndrome. Ann. Rheum. Dis. [Epub ahead of print], 2005.
8. Wang, S., Cukierman, E., Swaim, W.D., Yamada, K.M., and Baum, B.J. Extracellular matrix protein-induced changes in human salivary epithelial cell organization and proliferation on a model biological substratum. Biomaterials 20, 1043, 1999.

9. Aframian, D.J., Cukierman, E., Nikolovski, J., Mooney, D.J., Yamada, K.M., and Baum, B.J. The growth and morphological behavior of salivary epithelial cells on matrix proteincoated biodegradable substrata. Tissue Eng. 6, 209, 2000.

10. Baum, B.J, Wang, S., Cukierman, E., Delporte, C., Kagami, H., Marmary, Y., Fox, P.C., Mooney D.J., and Yamada, K.M. Re-engineering the functions of a terminally differentiated epithelial cell in vivo. Ann. N. Y. Acad. Sci. 875, 294, 1999.

11. Aframian, D.J., Tran, S.D., Cukierman, E., Yamada, K.M., and Baum, B.J. Absence of tight junction formation in an allogeneic graft cell line used for developing an engineered artificial salivary gland. Tissue Eng. 8, 871, 2000.

12. Tran, S.D., Wang, J., Bandyopadhyay, B.C., Redman, R.S., Dutra, A., Pak, E., Swaim, W.D., Gerstenhaber, J.A., Bryant, J.M., Zheng, C., Goldsmith, C.M., Kok, M.R., Wellner, R.B., and Baum, B.J. Primary culture of polarized human salivary epithelial cells for use in developing an artificial salivary gland. Tissue Eng. 11, 172, 2005.

13. Baum, B.J. Principles of saliva secretion. Ann. N. Y. Acad. Sci. 694, 17, 1993.

14. Turner, R.J., and Sugiya, H. Understanding salivary fluid and protein secretion. Oral Dis. 8, 3, 2002.

15. Melvin, J.E., Yule, D., Shuttleworth, T., and Begenisich, T. Regulation of fluid and electrolyte secretion in salivary gland acinar cells. Annu. Rev. Physiol. 67, 445, 2005.

16. Aframian, D.J., Redman, R.S., Yamano, S., Nikolovski, J., Cukierman, E., Yamada, K.M., Kriete, M.F., Swaim, W.D., Mooney, D.J., and Baum, B.J. Tissue compatibility of two biodegradable tubular scaffolds implanted adjacent to skin or buccal mucosa in mice. Tissue Eng. 8, 649, 2002.

17. Agre, P., King, L.S., Yasui, M., Guggino, W.B., Ottersen, O.P., Fujiyoshi, Y., Engel, A., and Nielsen, S. Aquaporin water channels-from atomic structure to clinical medicine. J. Physiol. 542, 3, 2002.

18. Shirasuna, K., Sato, M., and Miyazaki, T. A neoplastic epithelial duct cell line established from an irradiated human salivary gland. Cancer 48, 745, 1981.

19. Braddon, V.R., Chiorini, J.A., Wang, S., Kotin, R.M., and Baum, B.J. Adenoassociated virus-mediated transfer of a functional water channel into salivary epithelial cells in vitro and in vivo. Hum. Gene Ther. 9, 2777, 1998.

20. Zheng, C., and Baum, B.J. Evaluation of viral and mammalian promoters for use in gene delivery to salivary glands. Mol. Ther. 12, 528, 2005.

21. Kaludov, N., Handelman, B., and Chiorini, J.A. Scalable purification of adeno-associated virus type 2, 4, or 5 using ion-exchange chromatography. Hum. Gene Ther. 13, 1235, 2002.

22. Mitic, L.L., Van Itallie, C.M., and Anderson, J.M. Molecular physiology and pathophysiology of tight junctions I. Tight junction structure and function: lessons from mutant animals and proteins. Am. J. Physiol.Gastrointest. Liver Physiol. 279, G250, 2000.

23. Marzesco, A.M., Dunia, I., Pandjaitan, R., Recouvreur, M., Dauzonne, D., Benedetti, E.L., Louvard, D., and Zahraoui, A. 
The small GTPase Rab13 regulates assembly of functional tight junctions in epithelial cells. Mol. Biol. Cell. 13, 1819, 2002.

24. Voutetakis, A., Kok, M.R., Zheng, C., Bossis, I., Wang, J., Cotrim, A.P., Marracino, N., Goldsmith, C.M., Chiorini, J.A., Loh, Y.P., Nieman, L.K., and Baum, B.J. Reengineered salivary glands are stable endogenous bioreactors for systemic gene therapeutics. Proc. Natl. Acad. Sci. U. S. A. 101, 3053, 2004.

25. Kok, M.R., Voutetakis, A., Yamano, S., Wang, J., Cotrim, A., Katano, H., Bossis, I., Chiorini, J.A., Tran, S.D., Tak, P.P., and Baum, B.J. Immune responses following salivary gland administration of recombinant adeno-associated virus serotype 2 vectors. J. Gene Med. 7, 432, 2005.

26. Katano, H., Kok, M.R., Cotrim, A.P., Yamano, S., Schmidt, M., Afione, S., Baum, B.J., and Chiorini, J.A. Enhanced transduction of salivary glands with AAV5-based vectors. Gene Ther. [Epub ahead of print], 2005.

27. Zabner, J., Seiler, M., Walters, R., Kotin, R.M., Fulgeras, W., Davidson, B.L., and Chiorini, J.A. Adeno-associated virus type 5 (AAV5) but not AAV2 binds to the apical surfaces of airway epithelia and facilitates gene transfer. J. Virol. 74, 3852, 2000.
28. Delporte, C., Hoque, A.T., Kulakusky, J.A., Braddon, V.R., Goldsmith, C.M., Wellner, R.B., and Baum, B.J. Relationship between adenovirus-mediated aquaporin 1 expression and fluid movement across epithelial cells. Biochem. Biophys. Res. Commun. 246, 584, 1998.

29. Nagler, R.M., and Baum, B.J. Prophylactic treatment reduces the severity of xerostomia following radiation therapy for oral cavity cancer. Arch. Otolaryngol. Head Neck Surg. 129, 247, 2003.

30. Kok, M.R., Baum, B.J., Tak, P.P., and Pillemer, S.R. Use of localised gene transfer to develop new treatment strategies for the salivary component of Sjogren's syndrome. Ann. Rheum. Dis. 62, 1038, 2003.

Address reprint requests to:

Bruce J. Baum

GTTB, NIDCR, NIH, DHHS

Building 10, Room $1 N 113$

Bethesda, MD 20892-1190

E-mail: bbaum@dir.nidcr.nih.gov 


\section{This article has been cited by:}

1. E. L. SCHELLER, P. H. KREBSBACH, D. H. KOHN. 2009. Tissue engineering: state of the art in oral rehabilitation. Journal of Oral Rebabilitation 36:5, 368-389. [CrossRef]

2. Mrs. Swati Pradhan, Dr. Chu Zhang, Dr. Xinqiao Jia , Dr. Daniel Carson Ph.D. , Dr. Robert L Witt , Dr. Mary Cynthia Farach-Carson PhD . Perlecan domain IV peptide stimulates salivary gland cell assembly in vitroPerlecan domain IV peptide stimulates salivary gland cell assembly in vitro. Tissue Engineering Part A 0:ja. . [Abstract] [PDF] [PDF Plus]

3. Doron J. Aframian, Aaron Palmon . 2008. Current Status of the Development of an Artificial Salivary GlandCurrent Status of the Development of an Artificial Salivary Gland. Tissue Engineering Part B: Reviews 14:2, 187-198. [Abstract] [PDF] [PDF Plus]

4. Doron J. Aframian, Doron Amit, Ran David, Ela Shai , Dan Deutsch, Alexander Honigman , Amos Panet , Aaron Palmon . 2007. Reengineering Salivary Gland Cells to Enhance Protein Secretion for Use in Developing Artificial Salivary Gland DeviceReengineering Salivary Gland Cells to Enhance Protein Secretion for Use in Developing Artificial Salivary Gland Device. Tissue Engineering 13:5, 995-1001. [Abstract] [PDF] [PDF Plus] 